\title{
PRODUÇÃO DE HIDROGÊNIO A PARTIR DA MANIPUEIRA EM REATOR ANAERÓBIO DE LEITO FIXO
}

\author{
Nunes, A.N. ${ }^{1 *}$; Netto, A.P.O. ${ }^{1}$
}

1 Universidade Federal de Alagoas, 57.900-000, Maceió-AL, Brasil

*andressa_noe@hotmail.com

\begin{abstract}
RESUMO
A utilização de resíduos agroindustriais para produção de hidrogênio tem se mostrado uma tendência promissora, pois o seu descarte indevido gera problemas ambientais. O objetivo deste experimento foi avaliar a produção de hidrogênio a partir da manipueira em reator anaeróbio de leito fixo (RALF) operado sob aumento progressivo da taxa de carregamento orgânico (TCO) de 12 kg m-3.dia-1 a 96 kg m-3 dia-1 O material suporte foi argila expandida com diâmetro entre $2,8-3,35 \mathrm{~mm}$ e o reator foi inoculado com lodo anaeróbio suíno pré-tratado termicamente. $\mathrm{O}$ reator foi operado por 250 dias e o aumento progressivo da TCO foi realizado mantendo a
\end{abstract}

DQO afluente em $4000 \mathrm{mg}$. L-1 durante a operação do reator e variando o tempo de detenção hidráulica (TDH) de 8 horas até 1 hora. $\mathrm{O}$ rendimento máximo de hidrogênio foi obtido no TDH de $2 \mathrm{~h}$ (1,66 mol H2 mol-1 glicose). Os metabólitos solúveis presentes durante o funcionamento do reator foram ácido acético $(30,72 \%$ a $84,9 \%)$, ácido butírico $(2,89 \%$ a $29,13 \%)$, ácido propiônico $(3,98 \%$ a $13,09 \%)$, ácido capróico $(0,55 \%$ a $22,79 \%)$ e etanol $(3,64 \%$ a $10,46 \%)$. Apesar do prétratamento térmico do inóculo, foi observada a produção de metano juntamente com o hidrogênio em todas as fases operacionais.

PALAVRAS-CHAVE: Mandioca, biorreator, metabólitos.

\section{HYDROGEN PRODUCTION FROM CASSAVA IN ANAEROBIC FIXED BED REACTOR}

\begin{abstract}
The use of agro-industrial waste for the production of hydrogen has shown a very promising trend, because its improper disposal creates environmental problems. Thus, the objective of the research was to evaluate the production of hydrogen from cassava processing residue in anaerobic fixed bed reactor operated under progressively increasing organic loading rate (OLR) of 12 kg.m-3.d-1 a 96 kg.m-3.d-1. The support material for the adhesion of biomass was expanded clay with a diameter between $2.80-3.35 \mathrm{~mm}$, and the reactor was inoculated with anaerobic sludge pre heat-treated. The reactor was operated for 250 days and the progressive
\end{abstract}

increase of ORL was carried out keeping the COD affluent around $4000 \mathrm{mg}$. L-1, throughout the operation of the reactor and varying the hydraulic retention time (HRT) of 8 hours to 1 hour. The maximum yield of hydrogen was obtained in HRT of $2 \mathrm{~h}(1.66 \mathrm{~mol} \mathrm{H} 2 / \mathrm{mol}$ glucose). The soluble metabolites present during operation of the reactor were acetic acid $(30.72 \%$ to $84.9 \%)$, butyric acid (2.89\% to $29.13 \%)$, propionic acid (3.98 to $13.09 \%)$, caproic acid $(0.55 \%$ and $22.79 \%)$ and ethanol $(3.64 \%$ to $10.46 \%)$. Methane production was observed along with hydrogen in all operating phases.

KEYWORDS: Cassava, bioreactor, metabolites. 


\section{INTRODUÇÃO}

Segundo Martins (2003), a qualidade de vida do ser humano está diretamente ligada ao mundo em que vivemos e por isso o meio ambiente tem recebido grande importância atualmente. A atividade humana ocasionou um aumento das concentrações dos poluentes na atmosfera e agora ultrapassam os níveis-industriais estabelecidos. $\mathrm{O}$ aumento das concentrações destas substâncias na atmosfera, solos (e consequentemente nos vegetais) e em diversos materiais (como agentes de corrosão e degradação), é responsável por danos à saúde, ao meio ambiente (originando desequilíbrios nos ecossistemas) e aos patrimônios. Para amenizar este problema, a utilização de fontes alternativas de combustíveis que sejam limpas e sustentáveis oferece uma solução atraente para reduzir as emissões desses gases.

Diante deste cenário, o gás hidrogênio desperta interesse na comunidade científica, surgindo como uma fonte alternativa de energia em substituição aos combustíveis fósseis, que geram gases poluentes na sua combustão. O gás hidrogênio, segundo Santos (2005), gera principalmente vapor de agua e é 2,5 vezes maior do que o poder de combustão de combustíveis fósseis. Além disso, o hidrogênio pode ser produzido pela via fermentativa através de substratos ricos em matéria orgânica, como os resíduos agroindustriais, que são facilmente encontrados em todo o território brasileiro. Alagoas possui grande capacidade de produção de mandioca, visto que é a sua principal atividade econômica, tornando propício o desenvolvimento de pesquisas no estado.

Diversos são os trabalhos que demonstram a potencialidade do uso da manipueira para a produção de biohidrogênio. Amorim et al. (2013) avaliou a produção de hidrogênio a partir da manipueira em reator anaeróbio de leito fluidificado operado sob aumento progressivo da taxa de carregamento orgânico (TCO). Foi constatado que a produção volumétrica de hidrogênio aumentou de 0,20 até 2,04 L.h-1 L-1, quando foi reduzido o TDH de 8 h para 1 h. Lamaisona et al. (2009) encontrou o rendimento de 1,21 mol H2 mol-1 de glicose. Sreethawong et al. (2009) através de um processo sequencial de duas etapas utilizando fermentação anaeróbia e fermentação fotoheterotrófica para produzir hidrogênio a partir de mandioca e resíduos de alimentos encontrou um rendimento total de hidrogênio estimado em $810 \mathrm{ml} \mathrm{de} \mathrm{H2} \mathrm{g-1} \mathrm{de} \mathrm{mandioca.} \mathrm{Colin} \mathrm{et} \mathrm{al.} \mathrm{(2007),}$ através de um reator anaeróbio horizontal de escala laboratorial com empacotamento de bambu utilizando manipueira como substrato, atingiu a produção de 3,7 L de H2 L-1 dia-1. Entretanto, existem poucos trabalhos envolvendo reator de leito fixo comparada aos trabalhos que utilizam outros tipos de reatores para a produção de hidrogênio, principalmente utilizando manipueira como substrato.

Camilli e Pedroni (2005) fizeram uma comparação para avaliar o desempenho dos reatores CSTR, UASB e reator de leito fixo e apontaram que o reator de leito fixo apresentou melhor rendimento: 0,23L H2 g-1 de carboidrato. Essa constatação sugere que mais estudos devem ser realizados a fim de otimizar a produção de hidrogênio via reator anaeróbio de leito fixo. O objetivo principal deste trabalho é avaliar a geração de hidrogênio em reator anaeróbio de leito fixo a partir de águas residuárias geradas pelo processamento da mandioca para obtenção de subprodutos com valor agregado, como o próprio hidrogênio, e os álcoois e ácidos orgânicos provenientes da degradação anaeróbia (acético, butírico, propiônico, entre outros), buscando um processo de recuperação de energia voltado para a sustentabilidade ambiental e econômica no estado de Alagoas. 


\section{MATERIAIS E MÉTODOS}

\subsection{Inóculo e água residuária}

O lodo utilizado para a inoculação foi coletado em lagoa anaeróbia que trata resíduos de suinocultura localizada no bairro de Santa Amélia, Maceió/AL. Antes de ser utilizado, o lodo foi submetido a um aquecimento prévio por 10 minutos a uma temperatura de $90^{\circ} \mathrm{C}$ e resfriado em banho de gelo até atingir a temperatura de $25^{\circ} \mathrm{C}$, de acordo com a metodologia proposta por Maintinguer et al. (2008).

A água residuária utilizada neste trabalho foi a manipueira diluída a uma concentração de $4000 \mathrm{mg}$ L-1de DQO e suplementada com os seguintes nutrientes (mg L-1): CH4N2O, 125; NiSO4.6H2O, 1; FeSO4.7H2O, 5; FeCl3.6H2O, 0.5; CaCl2 6H2O, 47; CoCl2.2H2O, 0.08; SeO2, 0.07; KH2PO4, 85; KHPO4, 21.7; e Na2HPO4.2H2O, 33.4 (AMORIM et al, 2009). Foram realizadas 6 coletas de manipueira. As 5 primeiras coletas foram obtidas em uma pequena casa de farinha localizada no município de Santa Luzia do Norte e a última coleta foi realizada no município de Taquarana, ambos no estado de Alagoas. As principais características da manipueira são: pH 3,98, DQO 41,04 g L-1, Carboidrato Total 6,56 g L-1 e Ácidos voláteis 3,78 g HAc L-1

\subsection{Material suporte}

O material suporte escolhido para a adesão do biofilme foi a argila expandida (2.8-3.35 $\mathrm{mm}$ ), pois possui baixo custo, é de fácil obtenção e obteve bom desempenho assim como os estudos com o reator de leito fluidificado utilizado por Amorim (2013).

\subsection{Reator anaeróbio de leito fixo (RALF)}

O reator anaeróbio de leito fixo tem as mesmas características do reator de leito fluidificado utilizado por Amorim (2013). Construído em acrílico transparente com uma espessura de $5 \mathrm{~mm}$, possuindo uma altura de 190 centímetros e $5,3 \mathrm{~cm}$ de diâmetro interno. O volume total do reator é de $4192 \mathrm{~cm}^{3}$ e o volume útil é de $2200 \mathrm{~cm}^{3}$. O reator teve preenchimento total do leito com o material suporte, de acordo com procedimento, equivalente a $1,745 \mathrm{~kg}$. Entretanto, o leito não foi completamente preenchido, isso ocorreu devido aos ajustes dos vazios do leito ao receber a alimentação no início da operação

\subsection{Operação do reator}

$\mathrm{O}$ reator foi operado à temperatura ambiente por 250 dias e a variação da temperatura foi acompanhada por termômetro. A temperatura média de operação foi de $30,2^{\circ} \mathrm{C}$. $\mathrm{O} \mathrm{pH}$ durante a operação do reator não foi controlado, observando-se uma média do $\mathrm{pH}$ efluente próximo a $5,19 \pm$ 1,27 .

O inóculo foi desenvolvido em recipiente tampado (20L) contendo $15 \mathrm{~L}$ de solução de água residuária e inóculo. A proporção da solução foi composta por $10 \%$ de lodo suíno e $90 \%$ de água residuária do processamento da mandioca e suplementos. Neste experimento adotou-se o sistema de recirculação durante 48 horas entre o recipiente e o reator, buscando adaptar o lodo no próprio reator. A vazão de recirculação utilizada foi de $32 \mathrm{~cm}^{3} \mathrm{~s}-1$, correspondendo a uma velocidade de recirculação de 1,45 cm s-1, a mesma velocidade adotada por Amorim (2013). Ao final de 48 horas, o reator passou a ser operado com alimentação contínua através de uma bomba dosadora DOSITEC 
sob uma vazão de $524 \mathrm{~mL}$ h-1, que foi a vazão correspondente ao TDH de 8 h. Posteriormente, a vazão foi sendo incrementada de acordo com a redução do TDH para $6 \mathrm{~h}, 4 \mathrm{~h}, 2 \mathrm{~h}$ e $1 \mathrm{~h}$.

Um separador de gás-líquido foi utilizado para a coleta do efluente e do gás gerado. A produção volumétrica de biogás foi medida através do medidor MilliGas-counter, (Type TG1; Ritter Inc., Germany) acoplado a um recipiente contendo uma solução de hidróxido de sódio $(\mathrm{NaOH})$ com concentração de $5 \mathrm{~mol} \mathrm{~L}-1$. Ao realizar as medições, o biogás entra em contato com a solução de $\mathrm{NaOH}$ para que o gás carbônico $(\mathrm{CO} 2)$ formado fique retido na solução em forma de carbonato de sódio ( $\mathrm{NaCO} 3)$ e apenas o gás hidrogênio $(\mathrm{H} 2)$ seja medido.

\subsection{Análises químicas}

As análises físico-químicas foram realizadas periodicamente. As determinações de $\mathrm{pH}$, Demanda Química de Oxigênio (DQO), Sólidos Suspensos Totais (SST), Sólidos Suspensos Totais (SST) e Sólidos Suspensos Voláteis (SSV) foram realizadas de acordo com o APHA: Standard Methods for the Examination of Water and Wastewater (1998). Para os carboidratos foi utilizada a metodologia de Dubois et al. (1956). Além disso, a vazão, o pH e a temperatura eram medidos diariamente. As medições de absorbância das amostras de DQO foram realizadas usando o espectrofotômetro da Hach - DR 2500.

A determinação do $\mathrm{pH}$ foi realizada eletronicamente, utilizando o medidor de $\mathrm{pH}$. A composição do biogás foi monitorada por meio de cromatografia gasosa, através do método aplicado por Maintinguer et al. (2008), utilizando um cromatógrafo Shimadzu modelo GC 2010 (software GC Solution), com um detector de condutividade térmica e como gás de arraste o argônio (Ar).

As concentrações dos metabólitos solúveis foram monitoradas através do cromatógrafo Shimadzu (modelo GC 2010, software GC Solution) com detector de ionização de chama (FID) e coluna HP-INNOWAX de $30 \mathrm{~m}$ x 0,25 mm x 0,25 $\mu \mathrm{m}$, com hidrogênio como gás de arraste, através da metodologia validade por Adorno et al. (2014). Os ácidos orgânicos voláteis (acético, propiônico, butírico e capróico) foram determinados pelo método de extração com éter etílico. Os álcoois (etanol) foram determinados pelo método por headspace com injeção manual.

\section{RESULTADOS E DISCUSSÃO}

\subsection{Avaliação da eficiência de conversão do substrato em hidrogênio}

A partir da reação $(1) \mathrm{C} 6 \mathrm{H} 12 \mathrm{O} 6+2 \mathrm{H} 2 \mathrm{O} \rightarrow 2 \mathrm{CH} 3 \mathrm{COOH}+2 \mathrm{CO} 2+4 \mathrm{H} 2$, em que há a formação de acetato, pode-se observar que a produção teórica máxima de hidrogênio é de 4 mols H2.mol-1 glicose, portanto este foi o valor máximo considerado para o cálculo da eficiência. A quantidade de hidrogênio produzido foi inferida a partir do volume do biogás medido através do milligas. A produção de metano foi observada em todas as fases do reator, sendo importante destacar que o volume do biogás gerado, refere-se aos volumes de hidrogênio e metano produzidos, pois o $\mathrm{CO} 2$, que também é produto da biodigestão, fica retido na solução de $\mathrm{NaOH}$ na forma de $\mathrm{Na} 2 \mathrm{CO} 3$.

A Figura 1 mostra que a melhor produção de hidrogênio média (HPR) ocorreu na fase correspondente ao TDH de $1 \mathrm{~h}(0,0111 \mathrm{~L} \mathrm{~h}-1 \mathrm{~L}-1)$ e que o menor valor de HPR está associado aos valores de TDH de $6 \mathrm{~h}(0,00002 \mathrm{~L}$ h-1 L-1). Os baixos valores da produção volumétrica de hidrogênio estão associados ao grande percentual de produção de gás carbônico em todos os TDH's. O maior rendimento obtido foi no TDH de $2 \mathrm{~h}$, com valor de 1,66 mol de $\mathrm{H} 2 \mathrm{~mol}-1 \mathrm{de}$ 
glicose. Deve-se levar em conta que ao final da operação, no TDH de 1h, foi utilizada a sexta coleta de manipueira, que foi uma coleta com alto teor de matéria orgânica, o que ocasionou uma redução do rendimento de hidrogênio, pois as bactérias atingiram o seu limite cinético de utilização do substrato. Amorim (2013) e Zhang et al. (2006), operando reator anaeróbio de leito fluidizado verificaram rendimento máximo de produção de biohidrogênio de 2,04 H2 mol-1 de glicose e 1,19 mol de H2 mol-1 de glicose, respectivamente. Não foi possível a obtenção dos dados referentes ao TDH de 8 h devido aos problemas técnicos sofridos durante a operação do reator.

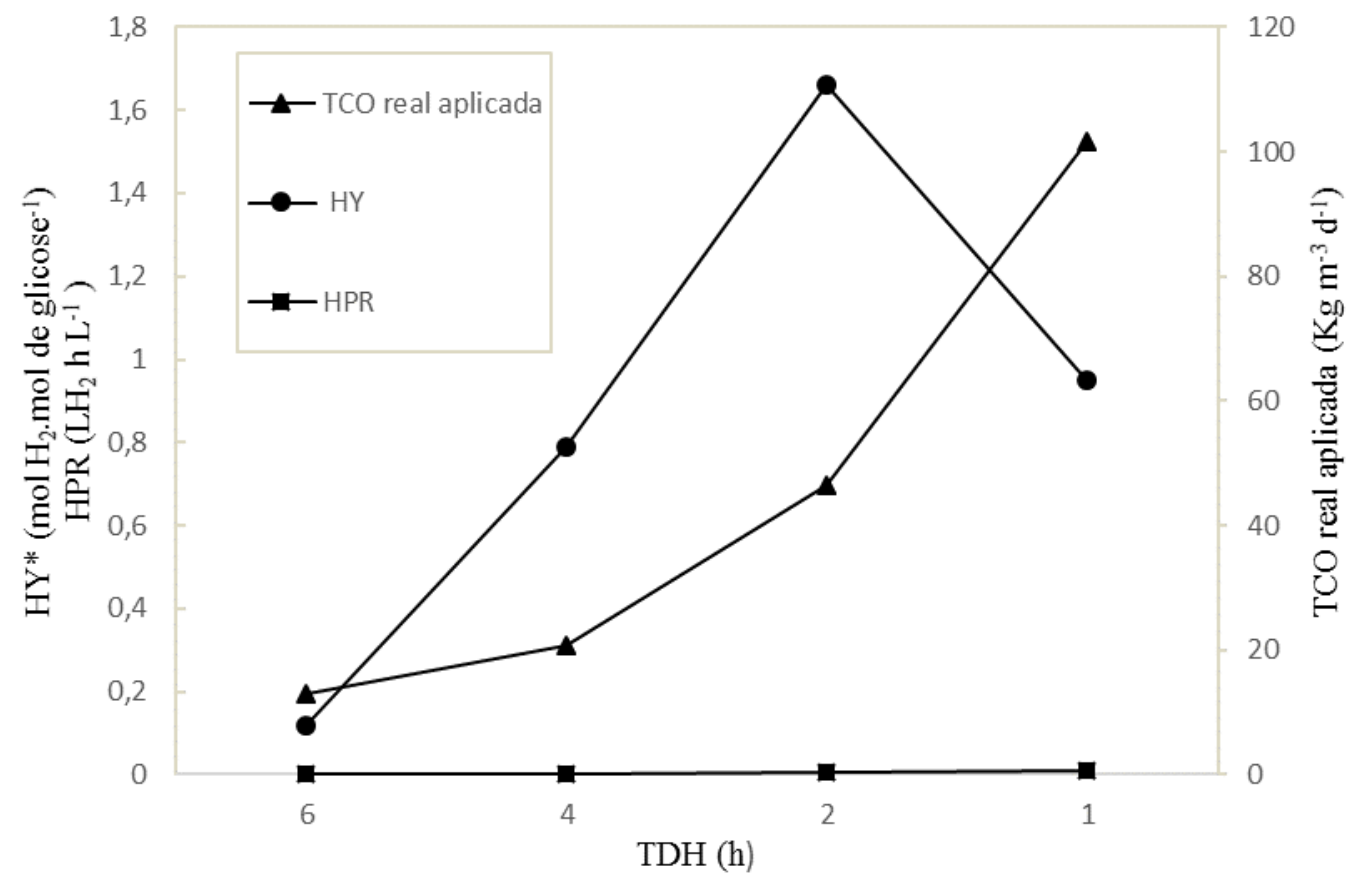

Figura 1: Variação da taxa de produção de hidrogênio (HPR), rendimento de hidrogênio (HY) e eficiência de conversão de cada fase do reator

Fonte: Autora, 2015

\subsection{Determinação da concentração de carboidratos}

A concentração média de carboidratos do afluente durante toda a operação foi de $560 \mathrm{mg} / \mathrm{L}$, com variação de 71,7 mg L-1 no TDH de 8h a $2472 \mathrm{mg}$ L-1 no TDH de $1 \mathrm{~h}$. O valor baixo no TDH de $8 \mathrm{~h}$ foi devido às dificuldades de armazenamento da manipueira e às suas próprias características; $\mathrm{o}$ alto valor no TDH de $1 \mathrm{~h}$ foi relativo à manipueira coletada em Taquarana que possuía alta concentração de carboidratos. O valor médio do efluente foi de $127 \mathrm{mg} \mathrm{L}-1$, com variação de 33,2 mg L-1 no TDH de $8 \mathrm{~h}$ a $839 \mathrm{mg} \mathrm{L-1}$ no TDH de $1 \mathrm{~h}$. Podemos observar as eficiências mais elevadas nos TDH's de $2 \mathrm{~h}$ e $4 \mathrm{~h}$. As eficiências de remoção de carboidratos para o TDH de $4 \mathrm{~h}$ e o TDH de $2 \mathrm{~h}$ estão bem próximas. Através do gráfico da Figura 2, podemos observar a transição do TDH de $2 \mathrm{~h}$ para o TDH de $1 \mathrm{~h}$ e o efeito que as diferentes coletas de manipueira ocasionaram na eficiência de remoção de carboidratos, ocasionando um choque no reator e diminuindo a sua eficiência, pois a carga orgânica é elevada para a capacidade dos microrganismos converterem o substrato, (LEITÃO et al, 2006b). De modo geral, a eficiência de remoção de carboidrato, neste trabalho, foi superior àquelas obtidas por Amorim (2013), pois o leito fixo, possui maior quantidade de argila expandida, se comparado ao de leito fluidificado em sistemas idênticos, possibilitando uma maior aderência de 
microrganismos aumentando a capacidade de utilização do substrato e, consequentemente, aumentando a sua eficiência.

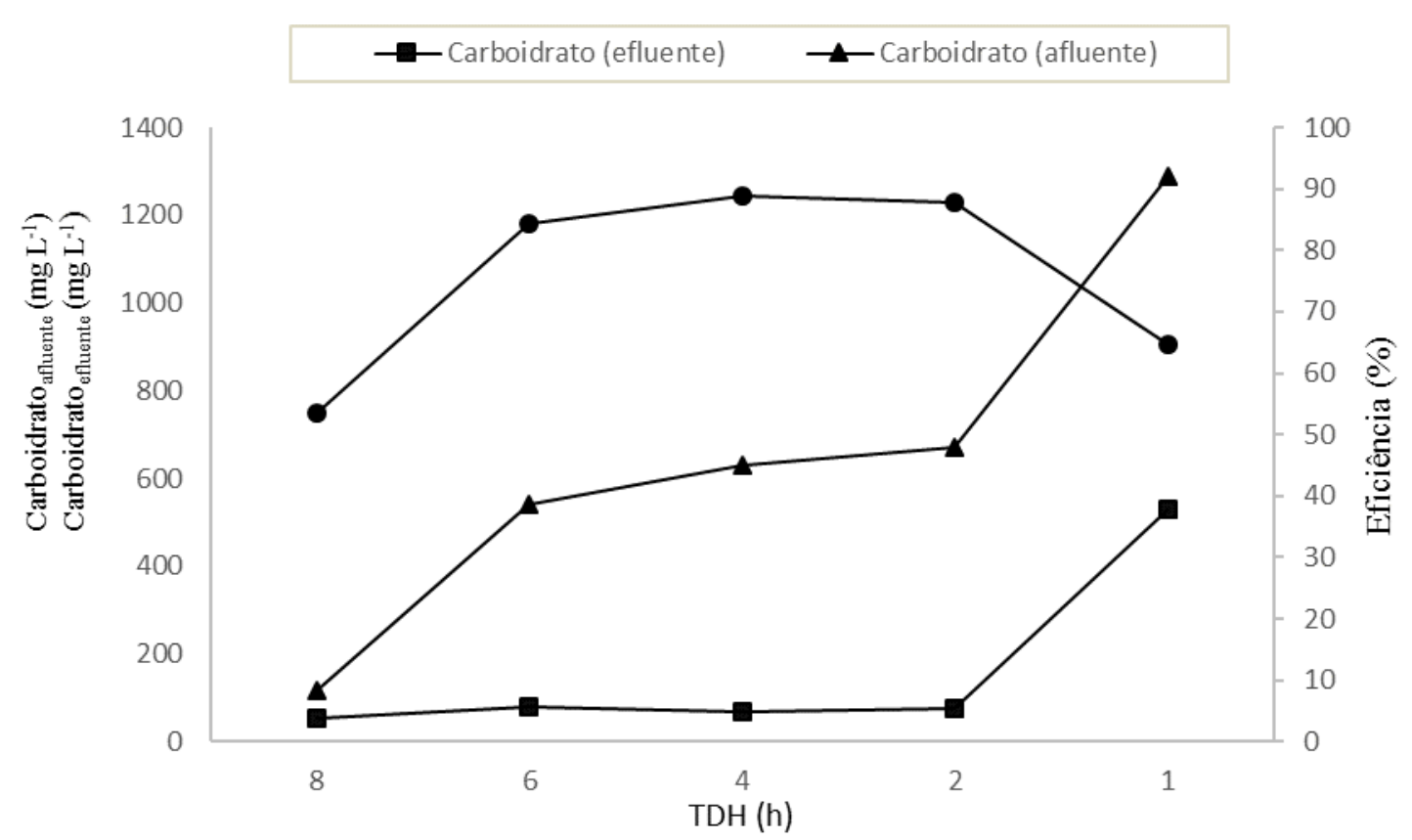

Figura 2: Carboidrato médio do afluente, carboidrato médio do efluente e eficiência em função do TDH.

Fonte: Autora, 2015

\section{3. Ácidos orgânicos voláteis e álcoois produzidos (metabólitos)}

Na Figura 19 é apresentado o gráfico das concentrações dos metabólitos líquidos detectados durante a operação do reator. Nota-se a presença de ácido acético (HAc), ácido butírico (HBu), ácido propiônico $(\mathrm{HPr})$, ácido capróico $(\mathrm{HCa})$ e etanol $(\mathrm{EtOH})$ em todas as fases operacionais do reator. $\mathrm{O}$ ácido acético foi encontrado em maiores concentrações em todas as fases, seguido do ácido butírico. Os ácidos acético e butírico são considerados indicadores da produção de hidrogênio, pois a rota metabólica desses produtos leva à formação de hidrogênio. Os ácidos acético e butírico apresentaram as maiores concentrações nos valores de TDH de $2 \mathrm{~h}$ (1351,99 mg L-1 e 434,18 mg L-1, respectivamente), entretanto o menor valor para o ácido acético foi encontrado no TDH de $6 \mathrm{~h}$ (148,05 mg L-1) e o menor valor para o ácido butírico foi encontrado no TDH $1 \mathrm{~h}$ (11,55 mg L-1), isso significa que devido ao baixo TDH, esses metabólitos não permaneciam no sistema tempo suficiente para serem degradados em moléculas menores pelos microrganismos, pois eram varridos do sistema, ocasionando a diminuição do rendimento de hidrogênio.

O TDH de $2 \mathrm{~h}$ exibiu o mais elevado rendimento de hidrogênio e através da Figura 3, podese observar que o ácido propiônico tem a menor participação do TDH de $2 \mathrm{~h}$ (3,98\%), o que corrobora para o melhor rendimento na produção de hidrogênio. Entretanto, no TDH de 1h, a participação do ácido propiônico aumenta, fazendo com que o rendimento de hidrogênio decaia. A rota do ácido propiônico é desfavorável, pois há o consumo de 2 mols de hidrogênio 


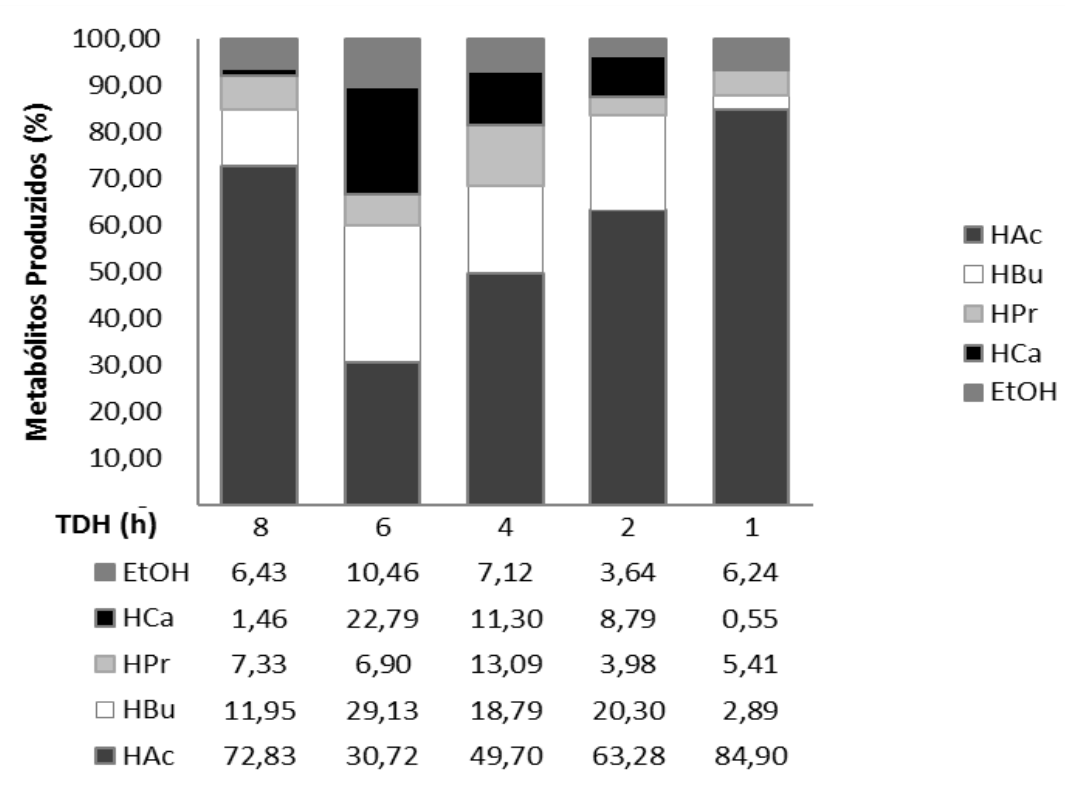

Figura 3: Participação dos metabólitos produzidos.

Fonte: Autora, 2015

\subsection{Remoção de DQO e balanço de massa}

Nesta pesquisa foi adotada a concentração afluente da manipueira em torno de $4000 \mathrm{mg}$ L-1, de acordo com Amorim (2009) A Figura 10 mostra a variação da DQO afluente, DQO efluente e a Eficiência de remoção, em função do TDH. A DQO afluente média foi 3386,3 mg L-1 e a DQO efluente média global foi de 2765,8 mg L-1. A DQO afluente variou de $1765,7 \mathrm{mg} \mathrm{L}-1$ (TDH 8h) a 5238,6 (TDH 4h), sendo o baixo valor da DQO no TDH de 8h. Observa-se que houve uma grande dificuldade em manter a DQO afluente em torno de $4000 \mathrm{mg} \mathrm{L}-1$. Isso se deve ao fato da utilização de um substrato real, com características difíceis de controlar e de difícil armazenamento, e também devido às peculiaridades da própria manipueira, que apresentou um aumento rápido do $\mathrm{pH}$, dificultando a manutenção da DQO.

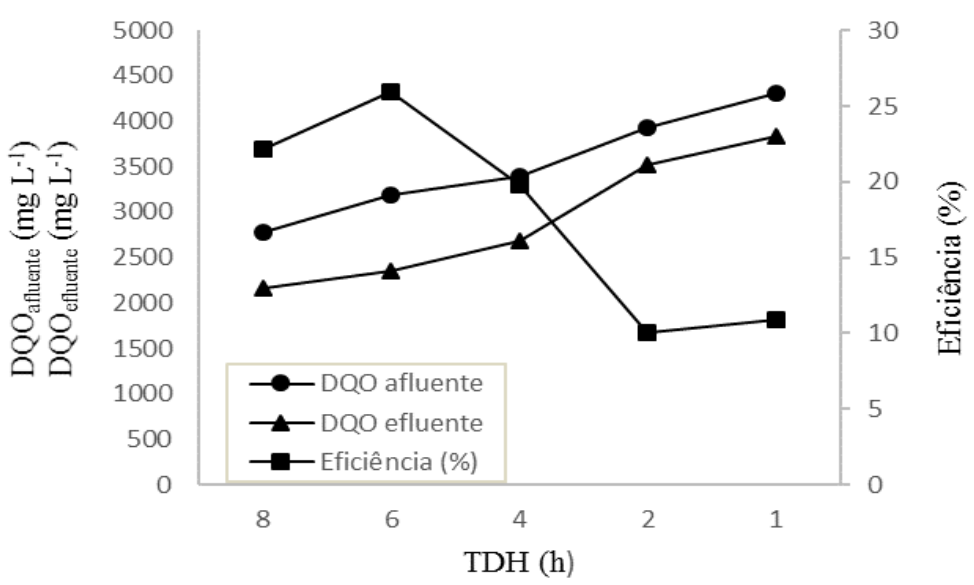

Figura 4-. DQO média do afluente e efluente e a taxa média de conversão de carboidrato.

Fonte: Autora, 2015 
A maior eficiência observada $(25,96 \%)$ foi no TDH de $6 \mathrm{~h}$, o mesmo foi observado em Amorim (2013). E a menor eficiência foi observada no TDH de $2 \mathrm{~h}$, pois neste TDH utilizou-se uma coleta de manipueira que possuía uma quantidade relativamente baixa de carboidratos, reduzindo a sua eficiência. Sabe-se que a matéria orgânica presente na manipueira, representada pelos valores de DQO, é constituída principalmente de amido e, consequentemente, glicose. Portanto, baixos valores de carboidrato afetam a eficiência de remoção de DQO. Na digestão anaeróbia completa a DQO é consumida para formar metano $(\mathrm{CH} 4)$ e dióxido de carbono (CO2). Mas, para a produção de hidrogênio, a DQO é pouco consumida, pois o hidrogênio é formado junto com os ácidos orgânicos, especialmente o ácido acético $(\mathrm{CH} 3 \mathrm{COOH})$ que ainda representa uma elevada $\mathrm{DQO}$, então valores altos de eficiência de remoção de DQO não significam necessariamente um bom indicador para a produção de hidrogênio. Desta forma, imagina-se que a baixa remoção de DQO deve-se justamente a produção de outros gases, especialmente o hidrogênio, sendo assim, a menor eficiência de remoção de DQO para a produção de hidrogênio, para este trabalho, foi encontrada no TDH de $2 \mathrm{~h}$, com 10,08\%. Lamaisona (2009) encontrou maior produção de hidrogênio com uma diminuição da DQO em torno de $20 \%$.

Para avaliar a eficiência de transformação do substrato em biogás, foi realizado um balanço de massa, levando-se em consideração as relações estequiométricas de oxidação da glicose, da biomassa descarregada do reator, do ácido acético, do ácido butírico, do ácido propiônico, do ácido capróico e do etanol. A DQO teórica foi calculada através da soma da DQO teórica da glicose, da DQO teórica da biomassa e da DQO teórica dos metabólitos descritas, esses valores podem ser observados na Tabela 1. A diferença entre a DQO do efluente medida e a soma de todas as DQOs teóricas tem um resultado positivo, no informa que alguns compostos podem não ter sido monitorados. A digestão anaeróbia é um processo biológico que converte compostos orgânicos complexos em $\mathrm{CH} 4$ e outros compostos como $\mathrm{CO} 2, \mathrm{~N} 2, \mathrm{NH} 3, \mathrm{H} 2 \mathrm{~S}$, traços de outros gases e ácidos orgânicos de baixo peso molecular, que podem não ter sido quantificados através dos métodos utilizados neste trabalho.

Tabela 1- Balanço de massa em termos da DQO para os resultados obtidos durante a operação do reator

\begin{tabular}{|c|c|c|c|c|c|c|c|c|c|c|}
\hline $\begin{array}{l}\text { TDH } \\
\text { (h) }\end{array}$ & $\begin{array}{c}\mathrm{DQO}_{\mathrm{t}} \\
\mathrm{HAC} \\
\left(\mathrm{mg} \mathrm{L}^{-1}\right)\end{array}$ & $\begin{array}{c}\mathrm{DQO}_{\mathrm{t}} \\
\mathrm{HBu} \\
\left(\mathrm{mg} \mathrm{L}^{-1}\right)\end{array}$ & $\begin{array}{c}\mathrm{DQO}_{\mathrm{t}} \\
\mathrm{HPr} \\
\left(\mathrm{mg} \mathrm{L}^{-1}\right)\end{array}$ & $\begin{array}{c}\mathrm{DQO}_{\mathrm{t}} \\
\mathrm{Hca} \\
\left(\mathrm{mg} \mathrm{L}^{-1}\right)\end{array}$ & $\begin{array}{l}\mathrm{DQO}_{\mathrm{t}} \\
\mathrm{EtOH} \\
\left(\mathrm{mg} \mathrm{L}^{-1}\right)\end{array}$ & $\begin{array}{l}\mathrm{DQO}_{\mathrm{t}} \\
\text { Glicose } \\
\left(\mathrm{mg} \mathrm{L}^{-1}\right)\end{array}$ & $\begin{array}{c}\mathrm{DQO}_{\mathrm{t}} \\
\text { Biomassa } \\
\left(\mathrm{mg} \mathrm{L}^{-1}\right)\end{array}$ & $\begin{array}{l}\mathrm{DQO}_{\mathrm{t}} \\
\text { Soma } \\
\left(\mathrm{mg} \mathrm{L}^{-1}\right)\end{array}$ & $\begin{array}{l}\mathrm{DQO}_{\text {efl }} \\
\left(\mathrm{mg} \mathrm{L}^{-1}\right)\end{array}$ & $\begin{array}{c}\mathrm{DQO}_{\text {efl }} \\
\mathrm{DQO}_{\mathrm{t}} \\
\text { soma }{ }_{1} \mathrm{mg} \mathrm{L}^{-}\end{array}$ \\
\hline 8 & 609,55 & 250,22 & 107,40 & 49,06 & 80,98 & 71,57 & 76,55 & $1.245,32$ & $2.074,66$ & 829,33 \\
\hline 6 & 157,82 & 374,57 & 62,12 & 469,01 & 80,82 & 69,63 & 145,04 & $1.359,02$ & $2.798,32$ & $1.439,30$ \\
\hline 4 & 375,44 & 355,10 & 173,20 & 341,98 & 80,86 & 75,86 & 185,33 & $1.587,78$ & $2.469,20$ & 881,42 \\
\hline 2 & 933,59 & 749,67 & 102,97 & 519,42 & 80,89 & 79,57 & 133,40 & $2.599,51$ & $3.363,76$ & 764,25 \\
\hline 1 & 731,44 & 62,37 & 81,68 & 19,13 & 80,84 & 852,46 & 342,47 & $2.170,39$ & $4.174,49$ & $2.004,10$ \\
\hline
\end{tabular}

Fonte: Autora, 2015

DQOt: Demanda química de oxigênio teórica;

HAc: acetato; HBu: butirato; HPr: propionato; HCa: hexanoato (ácido capróico) EtOH: etanol;

DQOt Soma: soma de todas as DQOt;

DQOefl: DQO do efluente medida; 


\section{CONCLUSÃO}

O RALF apresentou rendimento máximo da produção de hidrogênio de $41,5 \%$, a produção volumétrica de hidrogênio aumentou com o incremento da taxa de carregamento orgânico (TCO), tendo produção máxima no TDH de $1 \mathrm{~h}$, atingindo o valor de $0,01 \mathrm{~L} \mathrm{H} 2 \mathrm{~h} \mathrm{~L}-1$. O rendimento máximo observado em relação ao incremento da TCO foi de 1,66 mol H2 mol-1 de glicose quando aplicada uma TCO de 46,37 Kg m-3 d-1.

Obteve-se uma grande oscilação na concentração de carboidrato no afluente que variou de 71,69 mg L-1 no TDH de $8 \mathrm{~h}$ a $2471,8 \mathrm{mg}$ L-1 no TDH de $1 \mathrm{~h}$ respectivamente, sendo constatado que esta diferença de valores esteve relacionada às diferentes coletas de manipueira utilizadas para posterior alimentação do reator, essa variação teve influência em diversos parâmetros analisados neste trabalho. Entretanto as eficiências de remoção de carboidrato foram relativamente altas $(88,77 \%)$ comparadas às encontradas em trabalhos utilizando leito fluidificado. Amorim (2013) obteve máxima eficiência de remoção em torno de $65 \%$. O leito fixo possui maior quantidade de argila expandida, se comparado ao de leito fluidificado em sistemas idênticos, possibilitando uma maior aderência de microrganismos, aumentando a capacidade de utilização do substrato, que, consequentemente, aumenta a sua eficiência.

Os metabólitos solúveis detectados no efluente ao longo da operação do reator foram: Ácido Acético (30,72\% a 84,9\%), Ácido Butírico (2,89\% a 29,13\%), o Ácido Propiônico (3,98\% a $13,09 \%)$, o capróico $(0,55 \%$ a $22,79 \%)$ e o Etanol (3,64\% a 10,46\%). As rotas metabólicas levaram a produção de ácido propiônico na qual ocorre o consumo de hidrogênio, diminuindo os rendimentos do mesmo.

Apesar do pré-tratamento térmico do inóculo, as arqueias metanogênicas podem não ter sido eliminadas, visto que foi observada a produção de metano juntamente com o hidrogênio em todas as fases operacionais.

\section{REFERENCIAS}

ADORNO, M. A. T.; HIRASAWA, J. S.; VARESCHE, M. B. A. Development and Validation of Two Methods to Quantify Volatile Acids (C2-C6) by GC/FID: Headspace (Automatic and Manual) and Liquid-Liquid Extraction (LLE). American Journal of Analytical Chemistry, v.5, p.406-414, 2014.

AMORIM, E.L.C.; BARROS, A.R.; DAMIANOVIC, M.H.R.Z.; SILVA, E.L. Anaerobic fluidized bed reactor with expanded clay as support for hydrogen production through dark fermentation of glucose. International Journal of Hydrogen Energy, v.34, p.783-790, 2009.

AMORIM, N. C. S., ALVES, I., MARTINS, J. S., AMORIM, E. L. C. Biohydrogen production from cassava wastewater in an anaerobic fluidized bed reactor. Brazilian Journal of Chemical Engineering (Online), 2013.

APHA. Standard methods for the examination of water and wastewater. 19th. American Public Health Association. Washington, DC: American Public Health Association/American Water Works Association/Water Environmental Federation; 1998

CAMILli, M., PEDRONI, P. M. Comparison of the performance of three different reactors for BioHydrogen production via dark anaerobic fermentations PROCEEDINGS INTERNATIONAL HYDROGEN ENERGY CONGRESS AND EXHIBITION IHEC 2005 Istanbul, Turkey,13-15 July 2005.

COLIN, X.; FARINET, J.-L.; ROJAS, O.; ALAZARD, D.; Anaerobic treatment of cassava starch extraction wastewater using a horizontal flow filter with bamboo as support. Bioresource Technology, v.98, p. 1602 - 1607, 2007.

DUBOIS, S. M.; GILLES, K. A.; HAMILTON, J. K.; REBERS, P. A.; SMITH, FRED. Colorimetric Methods for determination of sugar and related substance. Analytical Chemistry, v. 228, p. 13-21. 1956. 
LAMAISONA, F., REGINATTOB, V., AMANTEC, E. R., ANTÔNIO R. V., Produção de Biocombustíveis a Partir da Água Residuária do Processamento da Mandioca. 2ND INTERNATIONAL WORKSHOP: Advances in Cleaner Production. São Paulo, Brasil. 22 a 23 de maio, 2009.

LEITÃO, R. C., et al, 2006b. The effects of operational and environmental variations on anaerobic wastewater treatment systems: a review. Bioresource Technology, Londres, v. 97, n.9, p. 1105-1118, $2006 \mathrm{~b}$.

MAINTINGUER, S. I. et al. Fermentative hydrogen production by microbial consortium. International Journal of Hydrogen Energy, v. 33, p. 4309-4317, 2008.

MARTINS, C. R.; PEREIRA, P. A. DE P.; LOPES, W. A.; ANDRADE, J. B. de; Ciclos Globais de Carbono, Nitrogênio e Enxofre: A importância da Química na Atmosfera, Cadernos Temáticos de Química Nova na Escola, v. 5, p. 28-41, 2003.

SANTOS, F. M. S. M. DOS; SANTOS, F. A. C. M. DOS; O Combustível "Hidrogénio", Millenium, v.31, p.252-270, 2005.

SREETHAWONG, T.; CHATSIRIWATANA, S.; RANGSUNVIGIT, P.; CHAVADEJ, S. Biological hydrogen production from cassava wastewater using an anaerobic sequencing batch reactor: effects os operational parameters, COD: N ratio and organic acid composition. Int. J. Hydrogen Energy 35 (9), 4092 - 4102, 2009.

ZHANG, Z. P.; SHOW, K. Y.; TAY, J. H.; LIANG, D. T.; LEE, D. J.; JIANG, W. J. Effect of hydraulic retention time on biohydrogen production and anaerobic microbial community. Process Biochemistry, v.41, n.10, p.2118-2123, 2006. 